\title{
A INTEGRALIZAÇÃO DAS INFORMAÇÕES CONTÁBEIS: ESOCIAL E CONTABILIDADE
}

\section{ARTIGO ORIGINAL}

BARBOSA, Nathália Teixeira ${ }^{1}$, SOUSA, Valéria da Rocha Breves de ${ }^{2}$, ROBERTO, José Carlos Alves ${ }^{3}$, SERRA, Meg Rocha da Cunha ${ }^{4}$, LOPES, Nelânia Ferreira ${ }^{5}$

BARBOSA, Nathália Teixeira. Et al. A integralização das informações contábeis: eSocial e contabilidade. Revista Científica Multidisciplinar Núcleo do Conhecimento. Ano. 06, Ed. 11, Vol. 10, pp. 162-181. Novembro 2021. ISSN: 24480959, Link de acesso: https://www.nucleodoconhecimento.com.br/contabilidade/aintegralizacao, DOI: 10.32749/nucleodoconhecimento.com.br/contabilidade/aintegralizacao

\section{RESUMO}

O eSocial foi criado pelo governo com o intuito de facilitar o compartilhamento de dados. Esse sistema possui similaridades com a Contabilidade e essa característica faz com que ambos se tornem importantes na inserção das informações. Neste contexto, levantou-se a seguinte problemática: ao utilizar o eSocial na Contabilidade, a integralização das informações torna-se otimizada? Assim, o presente artigo, tem como objetivo, analisar o eSocial em consonância com a Contabilidade na integralização das informações. Para melhor investigar a temática foi realizada uma pesquisa bibliográfica. Com base na pesquisa, os dados apontam o quão relacionado está o sistema do eSocial à Contabilidade, os quais se tornam grandes facilitadores no compartilhamento de dados, integralizando informações e

\footnotetext{
${ }^{1}$ Graduanda do curso de Ciências Contábeis.

${ }^{2}$ Coorientadora. Especialização em Língua Portuguesa e Literatura.

${ }^{3}$ Orientador. Mestre em Engenharia de Produção. Especialista em Logística empresarial. Graduado em Administração com ênfase em Marketing.

${ }^{4}$ Orientadora. Mestra em Engenharia de Processos Industriais pela UFPA, especialista em Controladoria e Auditoria Contábil pelo Ciesa (2020), Graduada em Ciências Contábeis pelo Centro Universitário do Norte (2010). Graduada em Ciências Econômicas pelo Centro Universitário do Norte (2006).

${ }^{5}$ Especialista em Auditoria Contábil, Financeira e Tributária e Graduada em Ciências Contábeis.
}

RC: 101749

Disponível em: https://www.nucleodoconhecimento.com.br/contabilidade/aintegralizacao 
otimizando tempo, tanto para os gestores quanto para profissionais de contabilidade, além de economizar custos com papéis e espaços físicos. Ao final concluiu-se que embora o sistema apresente certa complexidade em seu manuseio, notou-se que os benefícios de sua utilização ultrapassam qualquer uma das desvantagens existentes, já que todo e qualquer sistema sempre apresentará vantagens e desvantagens.

Palavras-Chave: eSocial, Contabilidade, Sped, Integralização, Informações.

\section{INTRODUÇÃO}

Todo trabalho dentro da contabilidade necessita de otimização e isso faz com que a tecnologia seja vista como a maior aliada desta área, pois as ferramentas tecnológicas utilizadas pela contabilidade facilitam a organização de toda uma empresa. Nesse sentido, uma das ferramentas que possibilita a comunicação do governo com empregados e empregadores é o eSocial, uma ferramenta digital que possui inúmeras vantagens e é aliada da contabilidade, sobretudo na organização de informações ligadas à empresa, ao empregado ou empregador.

Aponta-se o eSocial e a Contabilidade como ferramentas necessárias à integralização das informações, tendo o seu surgimento, suas funções, vantagens e desvantagens, cronograma e penalidades semelhantes. O conceito de contabilidade tem relação com o eSocial, sobretudo no que tange ao processo de distribuição de dados voltado à integralização das informações, tendo relação direta, portanto, com Sistema Público de Escrituração Digital e com a Escrituração Digital da Folha de Pagamento, realçando que todos são partes essenciais para o processo de tomada de decisão na entidade.

Para Menezes et al. (2019, p. 16), "Um problema de natureza científica deve apresentar uma relação entre as chamadas variáveis, ou seja, entre as propriedades ou características específicas de um dado fenômeno". Nesse sentido, o problema 
que norteará a pesquisa abordada é: ao utilizar o eSocial na Contabilidade, a integralização das informações torna-se otimizada?

O objetivo da presente pesquisa é analisar o eSocial em consonância com a Contabilidade na integralização das informações para que as informações se tornem padronizadas e de fácil compartilhamento.

Com este estudo, a comunidade acadêmica terá conhecimento relativo ao eSocial e a respeito de como a contabilidade é capaz de aumentar a eficiência da organização de informações. Os estudos também poderão ser utilizados como base para futuras pesquisas que se utilizem da mesma temática. Assim, utilizou-se como procedimento metodológico a pesquisa bibliográfica, de natureza qualitativa, a qual menciona obras e autores para embasamento da temática.

Destaca-se que tanto a Contabilidade quanto o eSocial possuem processos semelhantes de Escrituração, pois ambos precisam estar de acordo com legislações vigentes e, além disso, os dois também demonstram ter necessidade de realização de padronizações e otimizações.

\section{FUNDAMENTAÇÃO TEÓRICA}

De acordo com os dados coletados em livros, artigos e sites, o eSocial e a Contabilidade exercem papéis e objetivos semelhantes, e é com base nessas informações que observamos os pontos de ligação entre ambos.

Segundo Libório e Terra (2015, p. 40), fundamentação teórica "é a parte do desenvolvimento, onde o autor utiliza as afirmações de outros teóricos e conteúdos relacionados ao tema, seguindo uma sequência interativa".

Logo, a fundamentação é a revisão e exposição das pesquisas, resultados e questionamentos de outros autores a respeito do tema que será abordado e apresentado para os interessados e demais envolvidos. 


\subsection{ESOCIAL E SEU SURGIMENTO}

O eSocial é um projeto do governo, instituído pelo Decreto № 8.373 , de 11 de dezembro de 2014, que tem como objetivo coletar informações previdenciárias, fiscais e trabalhistas, entretanto, ele não realiza alterações na legislação, apenas auxilia na entrega de dados. Nibo (2014, p. 2) ainda enfatiza "que mesmo com a implementação do eSocial, a legislação continuará a mesma. O que muda é a forma de controle e fiscalização desses processos".

Entende-se que o eSocial incrementa o sistema de informação da Administração Pública e que, com isso, todas as informações inseridas nele se tornam de acesso exclusivo a usuários específicos. Logo, a quebra de sigilo de qualquer informação ou compartilhamento de dados sem autorização implica em infração, estando a pessoa ou empresa sujeitas às responsabilidades civis, administrativas e penais.

O sistema em questão é uma nova declaração acessória que inclui obrigações, a qual complementa o Sistema Público de Escrituração Digital. No entanto, essa declaração carrega consigo uma grande responsabilidade para que tudo esteja dentro das regras, ou seja, se o eSocial não for utilizado da maneira correta, não será possível realizar os recolhimentos previdenciários adequadamente.

Para Sousa e Orth (2020, p. 97), "trata-se de um programa que propõe facilitar os processos referentes à prestação de informações por meio da unificação e organização dos processos que funcionavam até 2017".

Sendo assim, o eSocial veio com o intuito de unificar as informações necessárias de uma forma totalmente nova e otimizada, com foco nas obrigações fiscais, trabalhistas e previdenciárias, para, assim, simplificar a gestão dos empregadores e, consequentemente, a vida dos funcionários, pois todos os dados se encontram interligados e permitem o fácil acesso, auxiliando em diversos processos burocráticos. 


\subsubsection{ESOCIAL E SUAS FUNÇÕES}

O eSocial foi criado com a intenção de otimizar e unificar o envio de documentos online e facilitar a entrega dos dados, para que eles possam ser enviados, mantendo, nesse processo, a qualidade no compartilhamento das informações, bem como para que as organizações e todos os que necessitam do programa possam cumprir os prazos estabelecidos.

Para Carvalho e Pimentel (2020, P. 12), "o eSocial é uma obrigação acessória composta de diversos arquivos a serem enviados. Esses arquivos contêm informações dos "eventos" trabalhistas, fiscais e previdenciários.

De acordo com Nibo (2014, p. 2), "Obrigações Acessórias existem em qualquer empresa, independente do seu porte, e se encontram no Código Tributário Nacional, e caso não sejam cumpridas, geram multas administrativas".

Percebe-se que esse sistema de informação foi implementado para: organizar, cadastrar e transmitir informações de forma clara e objetiva; para fiscalizar e reduzir sonegação e omissões; e para que tudo que for inserido esteja de acordo com a legislação, sobretudo no que se diz respeito à Previdência Social, Ministério do Trabalho, Receita Federal e Caixa Econômica.

O eSocial tem como função reduzir a quantidade de ocorrências. Alertas são emitidos quando se tem informações que possam não condizer com a realidade. $O$ CPF é utilizado como informação primordial em relação ao trabalhador e o eSocial possui um layout mais simples de ser entendido e manuseado. Desse modo, as informações são repassadas com maior veracidade e qualidade.

\subsubsection{VANTAGENS E DESVANTAGENS DO ESOCIAL}

Segundo Nibo (2014, p. 5), "na teoria o programa reduz a burocracia e torna mais simples os processos, porém na prática, trata-se de um aumento considerável na atenção envolvida em se administrar uma pequena empresa no Brasil".

RC: 101749

Disponível em: https://www.nucleodoconhecimento.com.br/contabilidade/aintegralizacao 
A unificação das informações torna-se um dos grandes pontos chaves do sistema, dentre os quais também se identificam: a otimização do tempo; redução dos custos e da burocracia no envio das informações; dados com menos erros e mais completos; atenção redobrada no momento de enviar relatórios, bem como maior agilidade nos processos. Também é um ponto positivo para a receita federal, pois a fiscalização das informações é realizada de forma mais rápida, dificultando, assim, que ocorra sonegação de impostos.

Com relação ao governo, ele se encontra como um dos maiores beneficiários, pois terá acesso a dados relacionados a economia, como: renda, emprego, mercado de trabalho e a redução do uso de materiais de escritórios. Além do aumento de espaços físicos, reduz-se, também, custos para o governo e entidades.

Conforme Oliveira (2018, p. 555), "a sensibilidade do Governo no cenário atual, sente a falta de padronização, resultando na duplicidade de dados, cada órgão exige as mesmas informações causando excessos das mesmas".

Outros pontos positivos desse sistema são: a redução de falhas nos registros da Previdência, a realização da entrega das obrigações de forma centralizada, a integralização dos sistemas e a padronização dos cadastros. Essas melhorias no sistema fazem com que ocorram menos erros e, consequentemente, menos problemas trabalhistas, fiscais, tributários e riscos de processos por informações errôneas.

Empregadores e empregados possuem maior segurança nos registros, evitando confusões a respeito das datas de entradas e saídas de empregados, dos benefícios a serem pagos, dos erros de rescisão, dos honorários e dos demais assuntos relacionados.

Como toda tecnologia, essa também tem suas desvantagens, uma delas é a sua complexidade em relação a padronização e digitalização das informações, pois as entidades que não conseguem se adequar ficam expostas ao não cumprimento dos prazos, o que torna o eSocial bastante exigente e detalhista.

RC: 101749

Disponível em: https://www.nucleodoconhecimento.com.br/contabilidade/aintegralizacao 


\subsubsection{CRONOGRAMA DE ENTREGA DO ESOCIAL: REGISTROS E PENALIDADES}

O cronograma passou a ser um item obrigatório desde 08 de janeiro de 2018, de acordo com o Governo Federal (2021). Atualmente, ele está dividido em 4 (quatro) grupos compostos por 4 (quatro) fases, sendo que cada fase equivale a uma obrigação a ser entregue, veja abaixo:

$\mathrm{Na} 1^{\underline{a}}$ fase são entregues informações relativas às empresas, como cadastros do empregador e tabelas.

$\mathrm{Na} 2^{2}$ fase as empresas são obrigadas a enviar informações relativas aos trabalhadores e seus vínculos com as empresas. Nesta fase, tem que enviar informações como: desligamentos, admissões e afastamentos.

$\mathrm{Na} 3^{a}$ fase torna-se obrigatório o envio das folhas de pagamento.

$\mathrm{Na} 4^{\mathrm{a}}$ fase todos os dados de segurança e saúde no trabalho (SST) deverão ser enviados.

Quadro 1 - Cronograma eSocial

\begin{tabular}{|c|c|c|c|c|}
\hline CRONOGRAMA & TABELAS & $\begin{array}{l}\text { EVENTOS } \\
\text { NÃO } \\
\text { PERIÓDICOS }\end{array}$ & $\begin{array}{l}\text { EVENTOS } \\
\text { PERIÓDICOS }\end{array}$ & $\begin{array}{l}\text { EVENTOS } \\
\text { DE SAÚDE } \\
\text { E SEG. NO } \\
\text { TRABALH } \\
\text { O }\end{array}$ \\
\hline GRUPO 1 & & 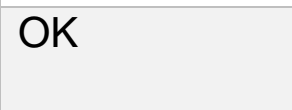 & & \\
\hline $\begin{array}{l}\text { GRANDES } \\
\text { EMPRESAS }\end{array}$ & $\begin{array}{l}\text { 2018/JANEIR } \\
\text { O }\end{array}$ & 2018/MARÇO & 2018/MAIO & OUTUBRO \\
\hline
\end{tabular}

RC: 101749

Disponível em: https://www.nucleodoconhecimento.com.br/contabilidade/a- 


\begin{tabular}{|c|c|c|c|c|}
\hline $\begin{array}{l}\text { GRUPO } 2 \\
\text { DEMAIS } \\
\text { EMPRESAS }\end{array}$ & $\begin{array}{l}\text { OK } \\
\text { 2018/JULHO }\end{array}$ & $\begin{array}{l}\text { OK } \\
\text { 2018/OUTUBR } \\
\text { O }\end{array}$ & $\begin{array}{l}\text { OK } \\
\text { 2019/JANEIR } \\
\text { O }\end{array}$ & $\begin{array}{l}2022 \\
\text { JANEIRO }\end{array}$ \\
\hline $\begin{array}{l}\text { GRUPO } 3 \\
\text { EMPRESAS DO } \\
\text { SIMPLES }\end{array}$ & $\begin{array}{l}\text { OK } \\
\text { 2019/JANEIR } \\
\text { O }\end{array}$ & $\begin{array}{l}\text { OK } \\
\text { 2019/ABRIL }\end{array}$ & $\begin{array}{l}\text { OK } \\
\text { 2021/MAIO }\end{array}$ & $\begin{array}{l}2022 \\
\text { JANEIRO }\end{array}$ \\
\hline NACIONAL & & & & \\
\hline $\begin{array}{l}\text { GRUPO } 3 \\
\text { PESSOAS } \\
\text { FÍSICAS }\end{array}$ & $\begin{array}{l}\text { OK } \\
\text { 2019/JANEIR } \\
\text { O }\end{array}$ & $\begin{array}{l}\text { OK } \\
\text { 2019/ABRIL }\end{array}$ & $\begin{array}{l}\text { OK } \\
\text { 2021/JULHO }\end{array}$ & $\begin{array}{l}2022 \\
\text { JANEIRO }\end{array}$ \\
\hline GRUPO 4 & OK & & & \\
\hline $\begin{array}{l}\text { ADM. PÚBLICA } \\
\text { E } \\
\text { ORG. }\end{array}$ & 2021/JULHO & NOVEMBRO & ABRIL & JULHO \\
\hline $\begin{array}{l}\text { INTERNACIONAI } \\
\mathrm{S}\end{array}$ & & & & \\
\hline
\end{tabular}

Fonte: www.gov.br

Ainda de acordo com o Governo Federal (2021), seguem abaixo os grupos onde cada entidade se encaixa, conforme seu faturamento e regime tributário ao qual fazem parte:

Fazem parte do Grupo 1 empresas que possuem faturamento anual superior a $R \$$ 78 milhões (setenta e oito milhões). 
Fazem parte do Grupo 2 as entidades empresariais cujo faturamento no ano de 2016 seja igual ou menor que $R \$ 78.000 .000,00$ e que não optem por uma Simples Nacional.

Fazem parte do Grupo 3 os empregadores optantes pelo Simples Nacional, empregadores, pessoa física (exceto doméstico), entidades sem fins lucrativos e produtor rural PF.

Fazem parte do Grupo 4 os órgãos públicos e organizações internacionais.

Portanto, é preciso que haja atenção aos prazos e às informações a serem enviadas, pois o cronograma existe com a finalidade de que todas as organizações e envolvidos se programem nas datas corretas.

Com relação às multas e possíveis penalidades devido a dados omissos, divergentes ou inexistentes, o eSocial torna-se bastante rigoroso nesse ponto, pois informações contraditórias, ou a falta delas, poderá causar grandes transtornos à entidade, que vão desde multas até possíveis paralisação das atividades.

Em casos de não envio das informações da FOPAG, por exemplo, a empresa pagará uma multa aproximada de pouco mais de $R \$ 1.800,00$. Já em casos de admissões, a entidade deverá realizar o envio das informações um dia antes do empregado iniciar suas atividades e, caso não haja o cumprimento desse prazo, a empresa poderá obter uma multa de $\mathrm{R} \$ 3.000,00$.

No caso de verbas rescisórias, o não pagamento no prazo estabelecido poderá acarretar multa de pouco mais de $R \$ 170,00$ por cada empregado, ou seja, a entidade terá que pagar as verbas mais as multas em cima de cada atraso.

Em relação aos casos de falta de atualização de dados cadastrais dos funcionários, o eSocial poderá aplicar uma multa no valor de $R \$ 600,00$, ou seja, qualquer alteração de salário, pedido de seguro-desemprego, acidente de trabalho, 
afastamento, férias, dentre outros, deverão ser atualizados e inseridos na escrituração do sistema.

\subsection{A CONTABILIDADE COMO FERRAMENTA DE OTIMIZAÇÃO DOS DADOS E SEU CONCEITO}

A Contabilidade nada mais é do que o registro de demonstrações contábeis, relatórios e demais dados para que a gestão de uma empresa tenha uma visão ampla do patrimônio da entidade e de todos os processos que norteiam a mesma. Sendo assim, pode-se afirmar que o objetivo da Contabilidade é dar apoio à tomada de decisões com base nas informações fornecidas para alcançar metas.

Para Barroso (2018, p. 13), "a Contabilidade é uma ciência social que possui como objeto de estudo o Patrimônio das entidades, tendo como um dos seus objetivos a divulgação financeira compreensível aos usuários para tomada de decisões".

$\mathrm{Na}$ contabilidade, existem os fatos contábeis, que são mensurados e registrados quando ocorrem ou quando são previstos, que acabam por provocar alterações ao patrimônio da entidade. Tais registros são computados cronologicamente e não podem deixar espaço para erros, pois podem causar alterações nos resultados, e a divergência desses dados pode implicar na falta de oportunidade para correção, e mesmo que haja a chance desses dados serem corrigidos, isso sempre implicará em certo ônus.

Para Martini (2013, p. 19), "fatos contábeis: são os eventos que provocam alteração do patrimônio das entidades. Exemplos: pagamento de salários, obtenção de empréstimo bancário, integralização de capital, compra de mercadorias". Já para Ribeiro (2018, p. 2), “a contabilidade é uma ciência social que tem por objeto o patrimônio das entidades econômico-administrativas, sendo seu objetivo principal, controlar o patrimônio das entidades em decorrência de suas mutações". 
A contabilidade, por meio do contador, tem o objetivo de controlar e gerenciar os dados, para que eles sejam inseridos e repassados para os interessados de forma clara e de fácil interpretação, diminuindo, também, a quantidade de papéis a serem enviados.

Portanto, a área contábil é de grande importância para as organizações e para todos aqueles que necessitam de planejamento organizacional para terem uma melhor gestão da posição financeira-econômica da entidade, e para aqueles que também necessitam se atualizar quanto às várias ramificações que a área engloba e quanto à veracidade das informações contidas. No capítulo a seguir, observar-se-á a relação da contabilidade com o eSocial e alguns pontos de similaridades.

\subsubsection{CONTABILIDADE VERSUS ESOCIAL}

Conforme Ribeiro (2018, p. 4), "a contabilidade abrange todos os órgãos econômicoadministrativos, pessoas físicas e jurídicas de direito público, como a União, os Municípios, os Estados, as autarquias e etc.".

Conforme as definições sobre contabilidade, seu objeto de estudo e a importância das informações coletadas, nota-se que ela complementa o eSocial na transmissão correta de informações aos usuários, principalmente no que tange à parte fiscal (tributos) e às obrigações trabalhistas, como pagamentos de salários, pois estes realizam alterações no patrimônio da empresa para o empresário.

Moura (2018, p. 5) "define os usuários das informações contábeis como pessoas físicas e jurídicas que as utilizam para registrar e controlar a movimentação de seus patrimônios, bem como aqueles que possuem interesse nesse controle".

O eSocial e a Contabilidade, como sistemas de informação, possuem o mesmo objetivo de auxiliar na tomada de decisão, porém, é necessário investir em capacitação profissional para que o contador esteja sempre atualizado, pois ele é o elo entre a correta coleta e transmissão de dados nos sistemas, bem como o braço direito da visão gerencial da entidade e de todos os envolvidos.

RC: 101749

Disponível em: https://www.nucleodoconhecimento.com.br/contabilidade/aintegralizacao 
A contabilidade é uma grande ponte entre a qualidade das informações e a transmissão delas para o eSocial, pois a maioria dos dados inseridos neste sistema passam pela análise gerencial da área contábil, para que, então, sejam finalizados e enviados para o sistema.

Nota-se que o eSocial gerou uma necessidade de reestruturação do método de trabalho na área contábil, como: adequação ao novo ambiente; qualificação profissional; acompanhamento constante das mudanças legislativas e evolução da tecnologia e do amplo mercado, que se faz obrigado a aderir a esse novo sistema. Ambos os sistemas apresentam similaridades que auxiliam os gestores e, por esse motivo, os profissionais devem sempre acompanhar as mudanças que podem causar impactos aos processos pertinentes à área.

\subsection{INTEGRALIZAÇÃO DAS INFORMAÇÕES}

Integralizar informações eletronicamente é um avanço tecnológico que veio para facilitar os processos existentes nas entidades, assim como para auxiliar na tomada de decisão, no desenvolvimento de um bom planejamento e na visão organizacional como um todo.

Segundo o dicionário Léxico (2009-2021), integrar é "tornar-se concluído, integral, inteiro, completar, complementar ou tornar-se inteiro, ser autossuficiente e pleno". Conforme a definição, a integralização das informações proporciona a unificação de sistemas que englobam informações como: relatórios, registros, demonstrações e demais dados para o controle e planejamento adequado das entidades e comércio em geral, auxiliando no dia a dia dos gestores, na otimização de atividades e na tomada de decisões, criando soluções com as informações coletadas e distribuídas. Com relação ao sistema, ele seria um conjunto de elementos organizados, enquanto a informação se refere à parte em que são distribuídos os elementos coletados e analisados. 
A integralização da informação (dentro de sistemas de informação) trabalha para que a entidade atinja um objetivo desejado, fazendo com que todos os dados contidos nela sejam explorados da melhor forma, isto é, para que se possa obter os resultados eficazes, claros e objetivos.

Para Alves (2005, p. 6), "afirma-se que a principal função do Sistema de informação é a transformação de dados em informações de fácil interpretação, que irá auxiliar os gestores na análise e na tomada de decisão".

Firmando-se nessa linha de raciocínio, um sistema de informação tem como função primordial facilitar o entendimento das informações e organizar cada item coletado de acordo com seu segmento e local, para que, assim, as informações de cada setor da entidade cheguem de forma clara e objetiva, alcançando o resultado esperado e o correto processo decisório da gestão.

Observa-se, então, a importância dos usuários por trás da inserção de dados. Para que tudo saia como o previsto, todos devem estar familiarizados com os sistemas e devem possuir total capacidade de entendimento sobre todos os dados coletados, para se possa realizar uma análise correta após a sua inserção. Sendo assim, cada item ou pessoa tem sua importância para o processo produtivo, e a unificação de dados por meio da integralização, como ocorre no eSocial e na Contabilidade, auxilia as organizações na redução de erros, não obtendo mais um sistema engessado.

\subsubsection{REGISTROS DE ESCRITURAÇÕES CONTÁBEIS}

Segundo Martini (2013, p. 6), "escrituração é o registro de eventos em livros impressos ou eletrônicos que alteram o patrimônio das entidades, para que tais informações assegurem a confiabilidade e a veracidade dos fatos contábeis".

Já para Ribeiro (2018, p. 44), "escrituração é uma técnica contábil que registra nos livros Diário, Razão, Caixa e etc., os fatos contábeis que ocorrem na entidade e que modifiquem ou possam vir a modificar o patrimônio da empresa".

RC: 101749

Disponível em: https://www.nucleodoconhecimento.com.br/contabilidade/aintegralizacao 
Alguns desses livros apontados por Ribeiro (2018) são: Livro Diário e Livro Razão, que se classificam como livros obrigatórios. Há, também, os livros auxiliares, que são: Livro Contas-Correntes, Livro Caixa, Contas a Receber, Contas a Pagar, dentre outros.

Percebe-se que a escrituração contábil corresponde a todos os acontecimentos que envolvem possíveis mutações no patrimônio de uma entidade e, por meio desses registros, ocorre a análise da situação financeiro-econômica. Além disso, ela também proporciona uma gestão mais competente do presente e futuro da entidade, trabalhando em cima de falhas e possíveis atrasos nas demandas.

No eSocial não é diferente, ocorre a escrituração digital de informações fiscais, trabalhistas e previdenciárias, informações como folha de pagamento, FGTS, cadastros de empregados, dentre outras, são necessárias para que todos os fatos que alterem os processos das entidades sejam inseridos e transmitidos para os órgãos fiscalizadores, com o objetivo de reduzir erros e omissões de dados. Com isso, ocorre a simplificação e padronização na entrega das obrigações acessórias e uma fiscalização mais certeira das obrigações previdenciárias e trabalhistas.

Enfatiza-se que a escrituração contábil compõe a vida da entidade. Todos os dados de situações passadas, presentes e futuras são registrados em livros próprios, tendo como objetivo o desenvolvimento de estratégias de crescimento e um melhor planejamento.

\subsubsection{SISTEMA PÚBLICO DE ESCRITURAÇÃO DIGITAL - SPED}

Para Geron et al. (2011, p. 47), "SPED é um instrumento que unifica atividades como validação, armazenamento e autenticação de livros e documentos integrantes da escrituração das empresas".

Criado pelo Decreto № 6.022, em 22 de janeiro de 2007, o SPED é um sistema de informação para melhorar a relação entre contribuintes e fisco. Sua função é modernizar o modo de transmissão de dados e unificar, por meio de certificação

RC: 101749

Disponível em: https://www.nucleodoconhecimento.com.br/contabilidade/aintegralizacao 
digital, informações relevantes para os órgãos interessados, afirmando a veracidade dos documentos e a validade jurídica.

Deu-se início ao SPED a partir de três projetos: Escrituração Fiscal Digital, Nota Fiscal Eletrônica e Escrituração Contábil Digital. Além disso, o sistema tem relação com as esferas estadual, federal e municipal, firmando parcerias com várias instituições, como associações, entidades civis etc.

O SPED tem vários benefícios, como a redução dos gastos com documentos impressos, o que, consequentemente, aumenta os espaços físicos nas empresas. As obrigações acessórias se tornam simplificadas, com menos custos, e as informações são padronizadas.

Quando se fala em acesso às informações, é válido citar que a evolução da era digital veio para facilitar as várias ramificações existentes, já que, na maioria das vezes, as mesmas informações geram um retrabalho enorme, assim como gasto maior de tempo. Seguem abaixo algumas vantagens do SPED:

Quadro 2 - Benefícios do SPED

\begin{tabular}{|l|l|}
\hline 1 & $\begin{array}{l}\text { Controle e fiscalização por meio de intercâmbio de informações entre as } \\
\text { administrações tributárias; }\end{array}$ \\
\hline 2 & Agilidade no acesso às informações; \\
\hline 3 & $\begin{array}{l}\text { Auditor com produtividade aumentada através da extinção dos passos para } \\
\text { coleta dos arquivos; }\end{array}$ \\
\hline 4 & Troca de informações entre os contribuintes a partir de um leiaute padrão; \\
\hline 5 & Custos administrativos menores; \\
\hline 6 & Informação com maior qualidade; \\
\hline 7 & Dados fiscais e contábeis interligados; \\
\hline 8 & Cópias autênticas e válidas da escrituração; \\
\hline
\end{tabular}


9 Aperfeiçoamento do combate à sonegação;

10 Preservação do meio ambiente pela redução do consumo de papel.

Fonte: sped.rfb.gov.br

Segundo o site do SPED [s.d.], ele tem como objetivo "promover a incorporação do fisco, tornar racionalizadas e uniformizadas as obrigações acessórias para os contribuintes e tornar mais ágil e eficaz a identificação de ilícitos tributários".

O SPED possui algumas bases para sua funcionalidade, veja abaixo:

Quadro 3 - Premissas do SPED

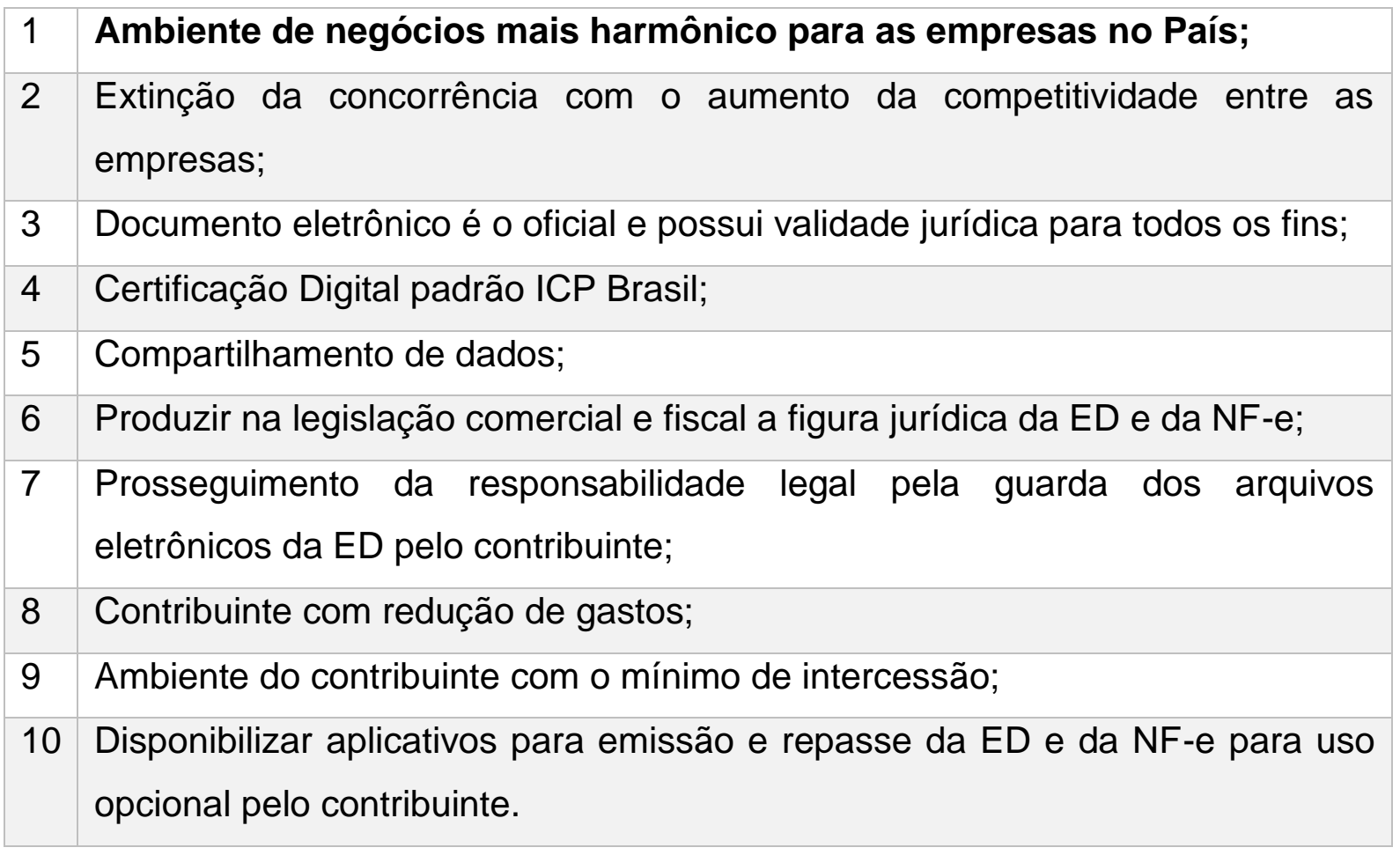

Fonte: sped.rfb.gov.br

Nota-se, então, que o SPED, assim como qualquer outro software, precisa de sistemas complementares para transmitir os dados necessários, sendo assim, as informações nele inseridas passam por uma análise e gestão de dados, 
ocasionando em um menor número de erros e ônus que essas falhas poderiam implicar, caso o software não fosse utilizado.

\subsubsection{ESCRITURAÇÃO DIGITAL DA FOLHA DE PAGAMENTO}

A Folha de Pagamento contempla os registros de todos os descontos e remunerações dos funcionários, e esses mesmos registros devem ficar disponíveis para fiscalização, se houver futuras auditorias, garantindo, assim, a continuidade da entidade em concordância com a legislação. Divide-se a folha de pagamento em duas partes: remuneração e descontos, como horas extras, adicionais, descontos por faltas, impostos etc.

Segundo Ribeiro (2018, p. 7), "proventos compõem: horas extras, adicional de insalubridade, salário, adicional de periculosidade, adicional noturno, salário-família, diárias para viagem, ajuda de custo, entre outros proventos previstos em lei".

Tais proventos trabalhistas devem ser inseridos na FOPAG Digital, referente à relação entre empregado e empregador, qualquer alteração de salário, entrada em seguros etc. Esses dados deverão ser computados no sistema e, para cada evento, gera-se um arquivo único. Quando ocorre uma admissão, o fato com os dados do empregado deve ser encaminhado antes que o mesmo inicie suas rotinas na empresa.

Conforme Oliveira (2017, p. 556), "o detalhamento das informações deve ser transmitido fundamentado no art. 32 da Lei oㅡ 8.212, de 24-7-1991. O número de arquivos transmitidos irá variar de acordo com o conteúdo informado".

Com isso, a transmissão dos dados deverá ser iniciada com o arquivo de abertura e ser finalizada com o de encerramento, e no decorrer do compartilhamento, caso um arquivo seja enviado com as mesmas informações mais de uma vez, o que foi inserido por último será o válido. 
Esses são alguns dos procedimentos para a Escrituração da Folha de Pagamento que deverão ser seguidos rigidamente para evitar que erros e dados inconsistentes sejam repassados aos sistemas e aos demais órgãos fiscalizadores, e para, também, evitar-se as omissões e possíveis desvios.

\section{MATERIAIS E MÉTODOS}

Para Pereira et al. (2018, p. 28), "o método científico é um trabalho sistemático, na busca de respostas às questões estudadas, é o caminho que se deve seguir para levar à formulação de uma teoria científica".

Apresenta-se aqui os procedimentos metodológicos referentes à natureza, aos fins e aos meios empregados pelo artigo. Logo, o objetivo da metodologia é descrever o tipo de pesquisa a ser realizada, seus meios e o objeto ou sujeito do estudo, para, a partir disso, delinear o caminho seguido.

\subsection{PROCEDIMENTOS METODOLÓGICOS}

Descreve-se os procedimentos metodológicos como o conjunto de ações que norteiam a pesquisa, que vão desde a escolha do método, tipologias, instrumentos e fontes, até às ferramentas que conduzem o conteúdo do trabalho.

Conforme Birochi (2015, p. 33), "cada caminho e cada escolha metodológica realizada pelo pesquisador pressupõe um conjunto de etapas a serem cumpridas. Essas etapas constituem o método científico".

\subsubsection{QUANTO À NATUREZA}

Segundo Flick (2013, p. 23), "a coleta de dados é concebida de uma maneira muito mais aberta e tem como objetivo um quadro abrangente possibilitado pela reconstrução do caso que está sendo estudado". 
Para Birochi (2015, p. 46), "uma vez decidido o tipo de abordagem do problema de pesquisa, o pesquisador deverá realizar algumas escolhas metodológicas, dentre elas as decisões relativas às estratégias de pesquisa".

Esta pesquisa possui natureza qualitativa, sendo que esta auxilia no entendimento do assunto por meio de dados e processos referentes ao objeto de estudo, às informações narrativas, à mensuração e, também, à descrição do tema escolhido. Os tipos de dados inseridos não utilizam um sistema número. A abordagem é do tipo subjetiva, com métodos flexíveis, a partir dos quais as estratégias adotadas para a coleta de informações são observadas e comentadas. Esse tipo de pesquisa visa sempre respeitar um roteiro, com o objetivo de garantir que todos os tópicos sejam abordados.

\subsubsection{QUANTO AOS FINS}

Para Barros, Rosa e Ribeiro (2017, p. 94), quanto aos fins, "permite descrever as características de determinadas populações ou fenômenos sociais ou organizacionais".

Para Del-Masso et al. (2014, p. 10), "a pesquisa descritiva tem por objetivo descrever as características do objeto que está sendo estudado e proporcionar uma nova visão sobre essa realidade já existente."

Firma-se a pesquisa de forma descritiva, para, assim, relacionar o eSocial à Contabilidade por meio dos dados coletados, dados esses que relacionam ambos em suas similaridades e contextos.

\subsubsection{QUANTO AOS MEIOS}

Para Zanella (2013, p. 36), "a principal vantagem é permitir ao pesquisador a cobertura mais ampla do que se fosse pesquisar diretamente; é relevante quando o problema de pesquisa requer dados muito dispersos". 
Conforme Sousa; Oliveira e Alves (2021, p. 66), "a pesquisa baseia-se no estudo da teoria já publicada, assim é fundamental que o pesquisador se aproprie do domínio da leitura do conhecimento e de todo o material que está sendo analisado".

A presente pesquisa possui caráter bibliográfico, baseando-se em livros, revistas, artigos e sites relacionados ao assunto do eSocial - suas vantagens e desvantagens, seu surgimento, cronograma, contabilidade e seu conceito e folha de pagamento digital -, para que, assim, fosse melhor construída a análise proposta. Esse é um dos primeiros passos da pesquisa.

\section{CONSIDERAÇÕES FINAIS}

Conclui-se, por meio desta pesquisa bibliográfica, que o eSocial foi desenvolvido com o intuito de inovar operando enquanto um sistema de informação integralizado, criado pelo governo a fim de facilitar o recebimento das informações fiscais, previdenciárias e trabalhistas pelos órgãos fiscalizadores. Foi abordada a implantação desse sistema dentro da contabilidade e como ambos, eSocial e Contabilidade, estão correlacionados na integralização das informações, a fim de evitar omissões e fraudes nas informações. Assim, percebeu-se como cada sistema possui uma ligação e similaridade no compartilhamento das informações, assim como preservam suas características próprias, porém, constatou-se que todos devem seguir a legislação vigente e cumprir prazos.

Notou-se que a evolução no compartilhamento de dados por meio de sistemas como eSocial, SPED e sistemas contábeis, como os registros de livro diário, razão e etc., fazem parte do coração de uma organização. Sendo assim, partindo das informações inseridas, é possível que se faça decisões que contribuam para o aprimoramento de uma boa gestão e um bom planejamento estratégico. Evidenciouse, com o objetivo geral, que o eSocial exerce relação com a contabilidade no que toca à integralização das informações e otimização delas. Partiu-se da problemática: ao utilizar o eSocial na Contabilidade, a integralização das informações torna-se otimizada? Observou-se como resposta para a problemática que o eSocial e a 
Contabilidade tornaram-se um grande elo entre as entidades, pois ambos proporcionam otimização do tempo e dos processos por meio da integralização das informações.

Dessa forma, a partir do exposto, notou-se que todos os dados trabalhistas, previdenciários e tributários são compartilhados de forma complexa e ao mesmo tempo, bem como, em virtude do eSocial, o processo se dá de forma mais completa e com menos erros. Esses sistemas de informações são uma evolução necessária para evitar dados inconsistentes ou a falta deles, e os órgãos fiscalizadores se tornam um dos maiores beneficiários, favorecendo o ganho de tempo e a análise de dados feita de maneira mais ágil e transparente. Conclui-se, com isso, que os estudos a respeito da temática são importantes agregadores de conhecimento acerca da evolução dos sistemas no compartilhamento de dados, sobretudo com o surgimento do eSocial, que, aliado à Contabilidade e ao SPED, exerce a função de facilitador de informações e de inserção de dados.

\section{REFERÊNCIAS}

BARROS, S.; ROSA, F.; RIBEIRO, E. Princípios e técnicas para elaboração de textos acadêmicos: pensando na Pós-Graduação. Salvador: UFBA, 2017.

BARROSO, D. Teoria da Contabilidade. Salvador: UFBA, 2018.

BIROCHI, R. Metodologia de estudo e de pesquisa em Administração. Florianópolis: Departamento de Ciências da Administração/UFSC, 2015.

ALVES, E. de. S. O Sistema de Informação Contábil como instrumento de gestão no Terceiro Setor. 2005. 44f. Monografia (Bacharel em Ciências Contábeis) - Universidade Federal de Santa Catarina, Florianópolis, SC, 2005.

CARVALHO, Z.; PIMENTEL, L. E-social - 10 boas práticas para evitar autuações. $4^{\mathrm{a}}$ ed. Florianópolis: Zenaide Carvalho, 2020. 
DEL-MASSO, M. C. S.; COTTA, M. A. de. C.; SANTOS, M. A. P. Ética em Pesquisa Científica: conceitos e finalidades. Redefor Educação Especial e Inclusiva, Texto II. São Paulo: Unesp, 2012.

FLICK, U. Introdução à metodologia de pesquisa: um guia para iniciantes. Porto Alegre: Penso, 2013.

GERON, C. M. S. et al. SPED-Sistema Público de Escrituração Digital: percepção dos contribuintes em relação aos impactos de sua adoção. Revista de Educação e Pesquisa em Contabilidade, v. 5, n. 2, p. 44-67, 2011.

GOVERNO. Cronograma de Implantação eSocial. Disponível em: https://www.gov.br/receitafederal/pt-br/assuntos/noticias/2021/julho/cronograma-deimplantacao-do-esocial-e-atualizado >. Acesso em: 22 ago. 2021.

LIBÓRIO, D.; TERRA, L. Metodologia Científica. São Paulo: Rede Internacional de Universidades Laureate, 2015.

LÉXICO. Conceito de Integralizar. Disponível em: https://www.lexico.pt/integralizar. Acesso em: 22 ago. 2021.

MARTINI, L. Contabilidade Geral. Belo Horizonte, MG: Educação Coletiva, 2013.

MENEZES, A. H. N. et al. Metodologia científica, teoria e aplicação na educação à distância. Petrolina - PE: Universidade Federal do Vale do São Francisco, 2019.

NIBO. eSocial 2014: aprenda as mudanças de forma fácil. 2014. Disponível em: https://www.nibo.com.br/wp-content/uploads/2014/04/eBook-eSocial.pdf. Acesso em: 30 ago. 2021.

OLIVEIRA, A. de. Cálculos trabalhistas. São Paulo: Atlas, 2011.

PEREIRA, A. S. et al. Metodologia da pesquisa científica. Santa Maria, RS: Universidade Federal de Santa Maria, 2018. 
RIBEIRO, O. Contabilidade Básica. 4를 ed. São Paulo: Editora Saraiva, 2018.

SOUSA, A.; OLIVEIRA, G.; ALVES, L. A pesquisa bibliográfica: princípios e fundamentos. Cadernos da FUCAMP, v. 20, n. 43, 2021.

SOUSA, T.; ORTH, A. Implementação do E-Social e seus impactos. Revista GEDECON-Gestão e Desenvolvimento em Contexto, v. 8, n. 1, p. 87-98, 2020.

SPED. Objetivo do SPED. Disponível em: http://sped.rfb.gov.br/pagina/show/964>. Acesso em: 22 ago. 2021.

ZANELLA, L. C. H. Metodologia de Pesquisa. $2^{a}$ ed. Florianópolis: Departamento de Ciências da Administração/UFSC, 2013

Enviado: Junho, 2021.

Aprovado: Novembro, 2021. 